\title{
Impact of Socio-Economic Development on Sustainable Business Development Among Small and Medium Scale Businesses in Nigeria
}

\author{
Kingsley Nwagu \\ Ph.D., Department of Management, School of Research, Texila American University
}

\begin{abstract}
This study is undertaken to investigate the impact of socio-economic development on sustainable business development among small and medium scale business in Nigeria. The significance of socioeconomic development in achieving sustainable business development among small and medium scale business, especially in a developing country like Nigeria, cannot be over-emphasized. This study employed a survey research design as data were elicited from the respondents who agreed to fill out the questionnaires. In this study, several socio-economic development indicator variables such as Selfreliance in Development, Policy Delivery Mechanism, and Access to Health Facilities were employed among others. The findings elicited from this study revealed that socio-economic development recorded a positive impact on sustainable business development among small and medium scale business in Nigeria.
\end{abstract}

Keywords: Access to Health Facilities, Policy Delivery Mechanism, Socio-economic development, Sustainable business development, Self-reliance in Development, Small and medium scale business.

\section{Introduction}

The role of small and medium scale enterprises in most of the developing nations cannot be overemphasized. [1] asserted that small and medium scale enterprises are deriver of growth and dominated the Nigerian economy. Small and medium scale enterprises contribute to the sustainable growth and development of developing countries through the creation of employment opportunities and contribution to gross domestic product.

Small and medium scale enterprises comprise of business that employed little capital for the establishment and operated small-scale boniness with the objective of making a profit. Small and medium scale enterprises have continued to increase and survive because they require little capital for the establishment, less labour, low technological knowledge, and little managerial capacity for establishment [2]. Also, small and medium scale enterprises are seen as a major tool for reducing unemployment and poverty through the generation of employment, contribution to rapid economic growth and export earnings, industrialization, and utilization of local resources.

Economic development is the desire of all nations of the world but how to attain sustainable economic development remains a challenge to many nations. Different paradigms of development are being considered globally, and one of such paradigms is sustainable development. Harmony between man and nature is the prerequisite for sustainable development. There is now a transition to an agenda that embraces the three dimensions of sustainable development while still ensuring that poverty eradication is its highest priority and that extreme poverty is ended within a generation. Until Nigeria begins to take this path, sustainable economic development will be a mirage.

Socio-economic development can be an integral driver of sustainable business 
development in a developing economy such as Nigeria. It is imperative for the government and or every other stakeholder in the economy to pursue business development through socioeconomic development. When social amenities such as a good road network, price stability, favourable business environment, and good government policies are put in place at optimum operation, sustainable development among small and medium scale business is inevitable. As mentioned earlier, it is not only a government responsibility to ensure socio-economic development, but the synergy of all the stakeholders involved in the economy.

This study is therefore undertaken to investigate the impact of various indicators of socio-economic development on sustainable business development among small and medium scale businesses in Nigeria via a survey research methodology. This study is broadly structured into five parts; the first part introduces the subject matter and gives an overview of socioeconomic development and sustainable business development among small and medium scale businesses in Nigeria. The second part handles the literature of this study, ranging from concepts of the subject matter to reviewing of past works on the subject matter, while the third part analyses the methodology employed in this study. The fourth part analyses the results of the respondents using statistical techniques to draw inference, and finally, the last part summarises the study and proffers recommendations that would aid Nigeria's economy attain sustainable business development among small and medium scale businesses in Nigeria via socio-economic development.

\section{The objective of the Study}

The objective of this study is to empirically investigate the impact of socio-economic development on sustainable business development among small and medium-scale businesses in Nigeria.

\section{Literature Review}

\section{What is Sustainable Development?}

Sustainability has been defined by [3] as the ability of a system to maintain a well-defined level of performance over time and, if required, to enhance output without damaging the essential ecological integrity of the system. In the opinion of [4], the concept of sustainability means that development efforts, including those aimed at protecting the health and the environment, should be undertaken in a manner that will not frustrate the ability of future generations to meet their needs. Environmental sustainability requires that the management of the environment should be in such a way that ensures that the environment and its natural resources give their optimum yield and are preserved for the benefit of both present and future generations. According to [5], it is the rate of renewable resource harvested, pollution creation, and non-renewable resource depletion that can be continued indefinitely. If they cannot be continued, then they are not sustainable. It is a development model that seeks the balancing of environmental protection against economic prosperity.

Sustainable development is the process of judicious use and conservation of natural resources for the overall improvement in the quality of life for the present and future generations on a long-term basis. The concept of sustainable development was formulated as a welding tool as well as a framework for the realization of economic growth in an environmentally viable world. Three interdependent and mutually reinforcing pillars of sustainable development are recognized worldwide in the transition towards a sustainable society. These are economic sustainability, environmental sustainability, and social sustainability. Within this concept, the environmental dimension plays a significant role, being the natural system, which serves as 
the surrounding medium in which the social and economic systems are embedded. The environment is a condition for sustainable development, and society is the end for which development is undertaken, and the economy is the means to achieving that end. The maintenance of the environmental structure is therefore crucial for long-term economic development [6]. Because life on earth is conditioned upon a healthy environment, the environmental pillar must of necessity be viewed as of utmost importance, providing the necessary foundation or stability for the economic and social pillars of sustainability.

\section{Economic Sustainability}

Environmental sustainability is the maintenance. Economic sustainability forms an important component of sustainable development. Economic sustainability is the maintenance and sustenance of a high real growth rate of the economy to achieve the development or economic objectives. Despite the huge resources in Nigeria, the country ranks low in economic performance [7].

Nigeria has not been able to maintain the growth rate necessary to reduce poverty. Nigeria suffers from a lack of balanced development where economic, social, and environmental dimensions are given due consideration for longterm sustainable development.

\section{Factors that Aids the Attainment of Sustainable Business Development}

\section{Sound Environmental Management}

The long-term viability of the Nigerian economy depends on sustainable and responsible management of the environment. The march towards attaining sustainable economic development starts of the integrity of different environmental media and systems to ensure that their functions and beneficial use are upheld for present and future generations.

\section{A Government that is Accountable}

Government must be willing to adopt effective and transparent public management of the economy.

Government must be prepared to provide a safe, stable, and attractive business and industry environment that will strengthen its ability to fulfill its responsibility for the welfare of the people. The absence of infrastructure is a chronic barrier to poor economic performance. Infrastructures like the availability of reliable energy and communication technologies that lead to more productive and innovative enterprises can also be provided by the government.

\section{Private Sector Engagement}

The private sector remains a driving force behind any sustainable economic development. Higher levels of growth and poverty reduction can be achieved in Nigeria giving the presence of a robust private sector.

Sustainable economic development can be stimulated by enhancing the productivity and competitiveness of enterprises so as to generate new formal employment opportunities. Nigeria should identify a few clusters which have the potential to grow and develop a comprehensive approach to encouraging the clusters to thrive.

This will help to overcome constraints faced by entrepreneurs, especially female entrepreneurs. Access to legitimate credit and financial services need to be increased.

Sustainable economic development requires sustainable enterprises. It requires a new way of doing business. It requires business enterprises to take steps to become greener in their operations as well as new and clean environmental technologies, with some companies specializing in their production while others are engaged in making use of such production.

[8] argues that sustainable economic transformation is key to a successful 21st- 
century economy. A new way of doing business is emerging out of this transformation. A new way of economic life that will empower Nigerians to meet their needs and still be able to conserve the earth and its resources for present and future generations is needed. One of the engines of transformation is green industries. The green industry is depicted in resource efficiency, pollution prevention, recycling, the minimization of waste, renewable energy transformation etc.

\section{Building Economic Foundations}

The right conditions and institutional frameworks upon which to encourage investment, innovation, and economic development need to be created. Capacity to ensure sound, transparent financial and economic management must be built while public policies that encourage private investment and reduce corruption must be enforced to the latter. This requires strong institutions and balanced laws as well as fair and effective regulatory regimes to oversee competition, the maintenance of standards, resource management, and property rights in the governing of the economy. Fair and equitable labour codes and laws will serve as empowerment to disadvantaged people in particular to ensure their engagement in the formal economy. This will enable them to have access to land and resources, security of tenure, and the capacity to make use of their assets in a more productive and sustainable manner. Government policies that open markets to trade and infrastructure investments are also required $[9,10]$.

\section{Effective Policies and Institutions}

It is not enough to make laws. The rule of law and political stability determine economic development. The stringent enforcement of these laws rather than the letters of the laws determines the effectiveness of such laws.

Policies that will support natural resource management and ensure environmental sustainability of economic activity and reinforce its long-term viability should be promoted. Nigerian government should be willing to build the necessary legislative and regulatory business, industrial and financial framework upon which sustainable growth can take place as well as effective mechanisms for enforcement. Transparent, appropriate regulatory systems, adequate and properly enforced laws as well as efficient fiscal management and resource allocation, sound public financial systems are all essential for stable economic development, the reduction of corruption, and making an economy sustainable. Local environmental officials, whose promotion is tied to effective enforcement of regulatory regime, should be legally empowered and made responsible for the enforcement of environmental standards.

\section{Increased Agricultural Productivity}

Agriculture remains the largest economic sector in many developing countries. It could be a significant generator of employment, contributing to poverty reduction and food scarcity. It is unfortunate to note that the ability of Nigeria to harness the growth potential of the agricultural sector can be retarded. Improvement in agricultural productivity and innovation can be a driver in economic development [11].

\section{Sustainable Socio-Economic Development}

This involves continuous improvement in the well-being and the standard of living of the people, which could be summarized in terms of income, health, education, environment, and freedoms. For the first three of these, per capita income, life expectancy at birth, infant mortality, and adult literacy are the proxies to be measured and compared. In other words, sustainable socioeconomic development is a process, which manages to combine the social, economic, and environmental aspects of development and establish a close link between these three pillars. Good governance, which is about appropriation, participation, responsiveness, accountability and sustainability. It constitutes the above link and 
one of the preconditions for sustainable development. Indeed, broad-based sustainable socio-economic development is by the people for the people, and the paradigm of building on the indigenous is, therefore, the necessary condition. The African masses themselves should own, participate and become the end and the means of their development. As indicated in the document on objectives, standards, criteria, and indicators for APRM, the socio-economic development section is intended to highlight efforts and progress made in designing appropriate policies and delivery mechanisms in key social development areas.

This effect, the following four objectives will be dealt with under this section:

Since economic growth alone does not automatically lead to sustainable socioeconomic development and the elimination of poverty, African heads of state and government adopted in 2001 the New Partnership for Africa's Development (NEPAD) with a view to eradicating poverty and alleviating other social and environmental impediments to sustainable growth and development. To this effect, the NEPAD underscores the importance of peace, security, democracy, sound economic management, human rights, and good governance as preconditions for sustainable development. Good governance is also endorsed by the African Peer Review Mechanism (APRM) [12].

The main objective of this mechanism, established in 2003 as part of the NEPAD, is to foster the adoption of policies, standards, and practices that lead to political stability, high economic growth, sustainable development, and accelerated sub-regional and continental economic integration. Good governance is characterized by appropriation, participation, responsiveness, accountability, and sustainability. It is therefore internationally considered as the underlying conceptualization of broad-based sustainable socio-economic development. Indeed, the promotion and acceleration of a broad-based sustainable socio- economic development will require a top-down and bottom-up approach in the formulation and implementation of policies and strategies geared towards reducing poverty and improving the overall well-being of the people. All stakeholders should own the whole process and actively participate in the promotion of selfreliance and capacity building for self-sustaining development.

To this effect, the country should first rely on its own resources and allocate them wisely for development programmes with particular emphasis on inter-related key priority sectors such as agriculture, environment, health, education, and infrastructure. Indeed, with a sharp population increase, land becoming less fertile, the disastrous over-exploitation of water and forest resources, and low rainfall in most parts of Africa, there has been increasing poverty and the downward spiral of underdevelopment. The poorer you become, the less you eat with less energy to work, and you do not produce enough and the poorer you become. In order to shift from the pitfall of underdevelopment and take-off, there should be a clean break in the vicious circle.

The broad-based sustainable socio-economic development together with its four objectives constitutes the pathway if policies and strategies are carefully formulated and implemented with a monitoring and evaluation system to measure the progress and take necessary corrective measures before it is too late. To this effect, adequate human resources should be identified and developed in each priority sector and in each discipline area in order to, among other things, engage all stakeholders individually and collectively in the whole process. In addition, adequate financial resources should be mobilized first at a national level then at regional and international levels to fill the needed gap. To ensure equity in the process, most disadvantaged people should be enabled to enhance their knowledge and manage their livelihoods, especially when development initiatives affect their lives. 
To this extent, the sustainable socio-economic development component of the APRM assessments is undertaken under a series of standards and codes, and objectives that are able to provide insight on the progress that African countries are making in terms of reducing inequalities, poverty, and hunger through the improvement of agriculture production, food security, environmental protection and affordable access to natural resources and basic services as development is about the well-being of present people without compromising the life of future generation [13].

To promote and accelerate broad-based sustainable socio-economic development objective deals with the way member countries formulate and appropriate policies and strategies for the promotion and acceleration of their socioeconomic development process. It is also intended to assess mechanisms and measures put in place for capacity building and financial resources mobilization, allocation, and management.

Participation of all stakeholders to the broadbased sustainable socio-economic development is very important as it involves people in the whole development process. Each citizen owns the concept and takes an active part in it. This second objective will therefore assess policies, strategies, and incentive measures put in place to stimulate participation from public servants, the private sector, civil society, and local communities.

Poverty, unemployment, and inequality are inter-related. It focuses on policies, strategies, mechanisms, and incentive measures geared towards reducing poverty and inequality through employment creation, education for all as well as access to national resources and basic services.

This objective attempt to measure the progress made towards gender equality with special emphasis on equal access to education for girls at all levels. It will ensure that gender equality is taken into account during the formulation and implementation of the national planning and development policies and strategies. It will try to understand how the government and other local stakeholders are combating gender inequality and giving equal rights, responsibilities, and opportunities to women and men, in particular to girls and boys, in terms of access to education $[14,15]$.

\section{Methodology}

This study adopted a survey research design. The population of this study comprised of selected SMEs owners, marketing managers, and sales managers in all the southeast states in Nigeria, who could provide relevant information for this study. 256 respondents were selected using a random sampling technique. Primary data was employed using research questionnaires to obtained relevant information from the respondents. However, statistical regression technique was employed for the purpose of analyzing the questionnaires and establishing the relationship between environmental factors, globalization, and small and medium scale enterprise's performance.

\section{Model Specification}

The model for the study is therefore stated thus in functional form:

$\mathrm{SED}=\mathrm{f}(\mathrm{SER}, \mathrm{SPE}, \mathrm{PDM}, \mathrm{ATF}, \mathrm{PGE}, \mathrm{BPD})$ (1)

$\mathrm{SED}=\boldsymbol{\alpha}+\beta_{1} \mathrm{SER}+\beta_{2} \mathrm{SPE}+\beta_{3} \mathrm{PDM}+\beta_{4} \mathrm{ATF}$ $+\beta_{5} \mathrm{PGE}+\beta_{6} \mathrm{BPD}(2)$

To account for other indices not included in the model we introduce the stochastic variable.

$\mathrm{SED}=\boldsymbol{\alpha}+\beta_{1} \mathrm{SER}+\beta_{2} \mathrm{SPE}+\beta_{3} \mathrm{PDM}+\beta_{4} \mathrm{ATF}$

$+\beta_{5} \mathrm{PGE}+\beta_{6} \mathrm{BPD}(3)$

Where:

SED = Socio-economic Development

SER = Self-reliance in Development

SPE $=$ Sustainable Development and Poverty Eradication

PDM = Policy Delivery Mechanism

ATF $=$ Access to Health Facilities

PGE $=$ Progress towards Gender Equality 


$\begin{array}{rlrl}\mathrm{BPD}= & \begin{array}{l}\text { Broad based participation in } \begin{array}{l}e \\ \text { Development }\end{array} \\ =\end{array} & \text { slope } & \text { which shows the influence of other indices } \\ \alpha & \text { affecting the dependent variable. } \\ \beta_{1}-\beta_{\mathrm{n}}= & \text { Coefficients }\end{array}$

\section{Data Analysis and Results}

Table 1. Model Summary

\begin{tabular}{|l|l|l|l|l|}
\hline Model & R & R Square & Adjusted R Square & Std. Error of the Estimate \\
\hline 1 & $.777^{\text {a }}$ & .603 & .599 & .66708 \\
\hline \multicolumn{2}{|l}{ a. Predictors: (Constant), SER, SPE, PDM, ATF, PGE, BPD } \\
\hline
\end{tabular}

Source: Researchers' Computation, 2021 using SPSS 20.0

Table 2. ANOVAa

\begin{tabular}{|l|l|l|l|l|l|l|}
\hline \multicolumn{2}{|l|}{ Model } & Sum of Squares & Df & Mean Square & F & Sig. \\
\hline \multirow{4}{*}{1} & Regression & 325.282 & 6 & 65.056 & 146.195 & $.000^{\mathrm{b}}$ \\
\cline { 2 - 7 } & Residual & 214.044 & 18990 & .445 & & \\
\cline { 2 - 6 } & Total & 539.326 & 18996 & & & \\
\hline \multicolumn{2}{|l}{ a. Dependent Variable: Socio-economic_Development } \\
\hline
\end{tabular}

Source: Researchers' Computation, 2021 using SPSS 20.0

Table 3. Coefficients ${ }^{\mathrm{a}}$

\begin{tabular}{|c|c|c|c|c|c|c|}
\hline \multirow{2}{*}{\multicolumn{2}{|c|}{ Model }} & \multicolumn{2}{|c|}{$\begin{array}{l}\text { Unstandardized } \\
\text { Coefficients }\end{array}$} & \multirow{2}{*}{$\begin{array}{l}\text { Standardized } \\
\text { Coefficients } \\
\text { Beta } \\
\end{array}$} & \multirow[t]{2}{*}{$\mathbf{T}$} & \multirow[t]{2}{*}{ Sig. } \\
\hline & & B & Std. Error & & & \\
\hline \multirow[t]{7}{*}{1} & (Constant) & .236 & .183 & & 1.284 & .200 \\
\hline & SER & .848 & .074 & .666 & 11.391 & .000 \\
\hline & SPE & .029 & .022 & .042 & 1.319 & .188 \\
\hline & PDM & .158 & .053 & .127 & 2.960 & .003 \\
\hline & ATF & .788 & .065 & .721 & 11.952 & .000 \\
\hline & PGE & .154 & .061 & .116 & 2.545 & .011 \\
\hline & BPD & .099 & .071 & .087 & 1.392 & .165 \\
\hline
\end{tabular}

Source: Researchers' Computation, 2021 using SPSS 20.0

The analysis result shown in Table 1, 2, and 3 above presents the result of the relationship between Socio-economic Development (SED) and various independent variables. The result of the regression estimates from Table 3 above indicates that there is a positive relationship between Socio-economic Development (SED) and Self-reliance in Development (SER). This is evidenced by the coefficient value of 0.848 . Statistically, the Sig. Value of 0.000 is lower than the acceptable significance value of 0.05 .
This means that Socio-economic Development (SED) significantly relates to Self-reliance in Development (SER). Sustainable Development and Poverty Eradication (SPE) has a coefficient value of 0.029 . Statistically, the Sig. Value of 0.188 is higher than the acceptable significance value of 0.05 . This means that SPE is not significantly related to SED.

Also, Policy Delivery Mechanism (PDM) was observed to be positively related to Socioeconomic Development (SED) with a coefficient 
value of 0.158 and a Sig. value of 0.003 . Access to Health Facilities (ATF) from the result has a positive and significant effect on Socioeconomic Development (SED). This is evidenced by a coefficient and Sig. value of 0.788 and 0.000 , respectively. Furthermore, Progress towards Gender Equality (PGE) has a coefficient value of 0.154 and a Sig. value of 0.011, indicating that PGE has a positive and significant effect on SED. Finally, Broad-based participation in Development (BPD) has a coefficient value of 0.099 and a Sig. value of 0.165 , indicating that BPD has a positive but insignificant effect on SED.

\section{Results and Discussion}

Nigeria as an economic entity is faced with the daunting task of achieving sustainable business development through the provision of key socio-economic indicator variables owing to the current pandemic ravaging the world economy. The impact of covid 19 on the Nigerian economy cannot be overlooked when discussing sustainable business development. The government is trying to steady the ship by harnessing the meager resources obtained as inflows to stabilize the economy, so in recent times, the pace of attaining sustainable business development not just in Nigeria but the world over has been greatly impaired. Key indicator variables of sustainable development such as sustainable development and poverty eradication has been at its lowest owing to the impact of the pandemic, hence the insignificant positive impact recorded in the model analysed in table 3 above. Other indicator variables such as selfreliance in development, policy delivery mechanism, access to health facilities, and progress towards gender equality all recorded significant positive relationships with socioeconomic development in Nigeria.

The overall significance of the model was observed to be a good fit. In other words, the goodness of fit of all the variables in the model was found out to be significant, as indicated by the F-stat. and its corresponding sign value, which shows that the model is a good fit at $1 \%$ and 5\% levels of significance.

Nigeria needs to adopt sustainable economic development strategies if she is not to be left behind in this era of sustainable revolution. Sustainable development, enabled by the integration of economic growth, social justice, and environmental stewardship, must be made the global guiding principle and operational standards.

Sustainable development is the partway to the future. This is the only framework that can bring together the full range of human aspirations and needs. It is a framework that offers a template for mutually reinforcing approaches to the challenges of the whole world.

\section{Conclusion}

Small and medium scale enterprises serve as an indispensable catalyst to economic growth in every nation due to their vast irreplaceable prospect in the economy. Small and medium scale enterprises possessed the potentials of creating employment opportunities, generating foreign earnings, and contributing to economic growth and development. Thus, the role of small and medium-scale enterprises in the development of most nations cannot be overemphasized. However, to be successful, small and medium scale operators must have a wide and adequate knowledge of the environment in which they operate.

The main objective of this study was to investigate the impact of socio-economic development on sustainable business development among small and medium-scale businesses in Nigeria. Several indicator variables of sustainable economic development were employed and subjected to empirical analysis via response elicited from respondent of the questionnaire administered; the results obtained suggested that socio-economic development had a positive relationship with sustainable business development among small and medium scale businesses in Nigeria. 


\section{Recommendations}

It is important to note that to achieve sustainable economic development, and there must be well organized sustainable economic development strategy. From the results obtained from the empirical analysis in this study, this study recommends as follow:

1. More effort should be made by the government and other stakeholders in the economy to further alleviate and possibly eradicate poverty; this would contribute towards the attainment of sustainable business development since people that are out of poverty level would have funds to start-up small and medium scale businesses.

2. The government and key policy makers in the economy should formulate and implement good economic policies which would bring about stability in the Nigerian economy and would further enhance sustainable economic development via the creation of more small and medium scale businesses.

3. In order for the Nigerian economy to attain sustainable business development, the government of Nigeria should pay more attention to the health care needs of her

\section{References}

[1] Ibrahim, U.A. (2015). External influence on the performance of small-scale businesses. Nigerian Journal of Management Technology \& Development, 6(2), 94-98.

[2] Essien, B.S. (2014). The Nigerian business environment and growth constraints of micro and small-scale manufacturing industries. American International Journal of Social Science, 3(6), 69-76.

[3] Evbuomwan, G. O., Ukeje, E. U., Moses F., Out, B. A. G., Amoo, E. A., Essien, L. ... Abba, M. A. (2003). Agricultural Development, Issues of Sustainability. In Nnanna, O. J., Alade, S. O., \& Odoko, F. O. (22.), Contemporary Economic Policy Issues in Nigeria. (pp. 185-194). Abuja: Central Bank of Nigeria. citizens. Access to Health Facilities should be non-negotiable since it is only a healthy person can engage in any productive business ventures.

\section{Conflict of Interest}

I hereby certify that, to the best of my knowledge: No financial support or benefits have been received by me, by any member of my immediate family, or any individual or entity with whom or with which I have a significant relationship from any commercial source which is related directly or indirectly to the work which is reported on in the article. I declare that I have no conflict of interest.

\section{Acknowledgement}

I acknowledge my brother and colleague Dr. Udeme, Okon Efanga for his contributions and materials supplied to me for this article.

Secondly, my deepest gratitude goes to my doctoral Guide/Supervisor, Professor James C. Ihemeje, Professor of Finance at Michael Okpara University of Agriculture Umudike, and my Co-Guide/Supervisor, Dr.N.S. Shanthi, for their guidance, scholarly support and dedication of time, without which this article would not have become a reality.

[4] Glenn, M. W., Magraw, Jr. D. B. (2005). Principles and approaches to sustainable development and chemicals management for a strategic approach to international chemicals management Centre for International Environmental Law (CTEL). Retrieved from https://www.ciel.org/wpcontent/uploads/2015/03/SA ICM_PrinciplesStudyFinal_July05.pdf.

[5] Daly, H. E. (1990). Towards some operational principles of sustainable development. Ecological Economics 2(1), 1-6.

[6] Babafemi, I.D. (2015). Bank management and rural economic development in Nigeria. Australian Journal of Business and Management Research, 4(9), 22-31. 
[7] Ranjani, K.S. (2012). Regulating microfinance institutions in India: A Conceptual framework. Synergy, 10(1), 78-89.

[8] Nixon, J. (2009). Sustainable Economic Development; Initiatives, Programs, and Strategies for Cities and Regions. Urban sustainability associates. $\quad$ Retrieved from https://globalurban.org/Sustainable\%20Economic\% 20Development.pdf.

[9] Adeola, A. (2016). Impact of external business environment on organisational performance of small and medium scale enterprises in Osun State, Nigeria. Scholedge International Journal of Business Policy \& Governance, 3(10), 55-166.

[10] Eruemegbe, G.O. (2015). Impact of business environment on organization performance in Nigeria: A study of union bank of Nigeria. European Scientific Journal, ESJ, 11(10), 478-494.

[11] Ndife, C.F. (2014). Business environment and survival of the tourism industry. Journal of Business and Management, 16(10), 78-83. Retrieved from https://eujournal.org/index.php/esj/article/view/6553
[12] Obasan, K.A. (2014). The impact of business environment on the survival of small-scale businesses in Nigeria. International Journal of Management and Business Research, 4(3), 165-170.

[13] Ikharehon, J.I., \& Briggs, A. (2016). The impact of strategic factors on the performance of small and medium scale enterprises in Nigeria: A study of some selected small and medium scale enterprises in Abuja. International Journal of Humanities and Social Science, 6(2), 140-149.

[14] Chukwuma, N.K., \& Chukwuma, E. (2015). Implications of economic factors on small scale business performance in Nigeria: 1970 - 2013. International Journal of Research in Business Management, 3(10), 23-30.

[15] Orogbu, L., Onyeizugbe, C.U., \& Chukwuma, E. (2017). The economic environment of small and medium scale enterprises: implications on economic growth in Nigeria. Journal of Economics, Management, and Trade, 19(4), 1-12. 